\title{
Refractive Index Sensing by High Aspect Ratio Titanium Nitride Trench Structures
}

\author{
Shkondin, Evgeniy; Repän, Taavi; Takayama, Osamu
}

\section{Published in:}

Novel Optical Materials and Applications 2018

Link to article, DOI:

10.1364/NOMA.2018.NoTh3D.3

Publication date:

2018

Document Version

Peer reviewed version

Link back to DTU Orbit

Citation (APA):

Shkondin, E., Repän, T., \& Takayama, O. (2018). Refractive Index Sensing by High Aspect Ratio Titanium Nitride Trench Structures. In Novel Optical Materials and Applications 2018 [NoTh3D.3] Optical Society of America (OSA). https://doi.org/10.1364/NOMA.2018.NoTh3D.3

\section{General rights}

Copyright and moral rights for the publications made accessible in the public portal are retained by the authors and/or other copyright owners and it is a condition of accessing publications that users recognise and abide by the legal requirements associated with these rights.

- Users may download and print one copy of any publication from the public portal for the purpose of private study or research.

- You may not further distribute the material or use it for any profit-making activity or commercial gain

- You may freely distribute the URL identifying the publication in the public portal 


\title{
Refractive Index Sensing by High Aspect Ratio Titanium Nitride Trench Structures
}

\author{
Evgeniy Shkondin, Taavi Repän, Andrei V. Lavrinenko, Osamu Takayama \\ Department of Photonics Engineering, Technical University of Denmark, \\ Ørsteds Plads, Building 343, DK-2800 Kgs. Lyngby, Denmark \\ Authore-mail address:alav@fotonik.dtu.dk
}

\begin{abstract}
Titanium nitride grating structures are fabricated by a combination of deep reactive ion etching and atomic layer deposition. Such structures being analyzed as an ambient medium sensor, exhibit the refractive index sensitivity of $430 \mathrm{~nm} / \mathrm{RIU}$. @ 2018 The Author(s)
\end{abstract}

OCIS codes: (050.1950) Diffraction gratings; (250.5403) Plasmonics; (160.4760) Optical properties; (240.0310) Thin films; (220.4241) Nanostructure fabrication; (280.4788) Optical sensing and sensors

Plasmonics, a field of nanophotonics where surface plasmons, collective oscillation of electron density, play a key role to confine light at the nanoscale, find promising applications in sensing [1]. Such plasmonic sensing devices have been developed to localize electric fields in very confined volumes close to the metal surfaces, thus tracing very small amounts of analytes in label-free biosensors. Grating sensors made of plasmonic (with a negative permittivity) [2] or dielectric [3] elements have been extensively studied for their potential of multiplexing of sensing units, achieving high throughput integration on lab-on-a-chip systems. They can contribute to design and production of point-of-care (POC) devices for swift, facile, and inexpensive diagnosis in future health care. Sensing elements, in general, require high robustness and stability, since, in many cases, they should sustain hours of continuous measurements, as well as made of cheap and abundant materials.
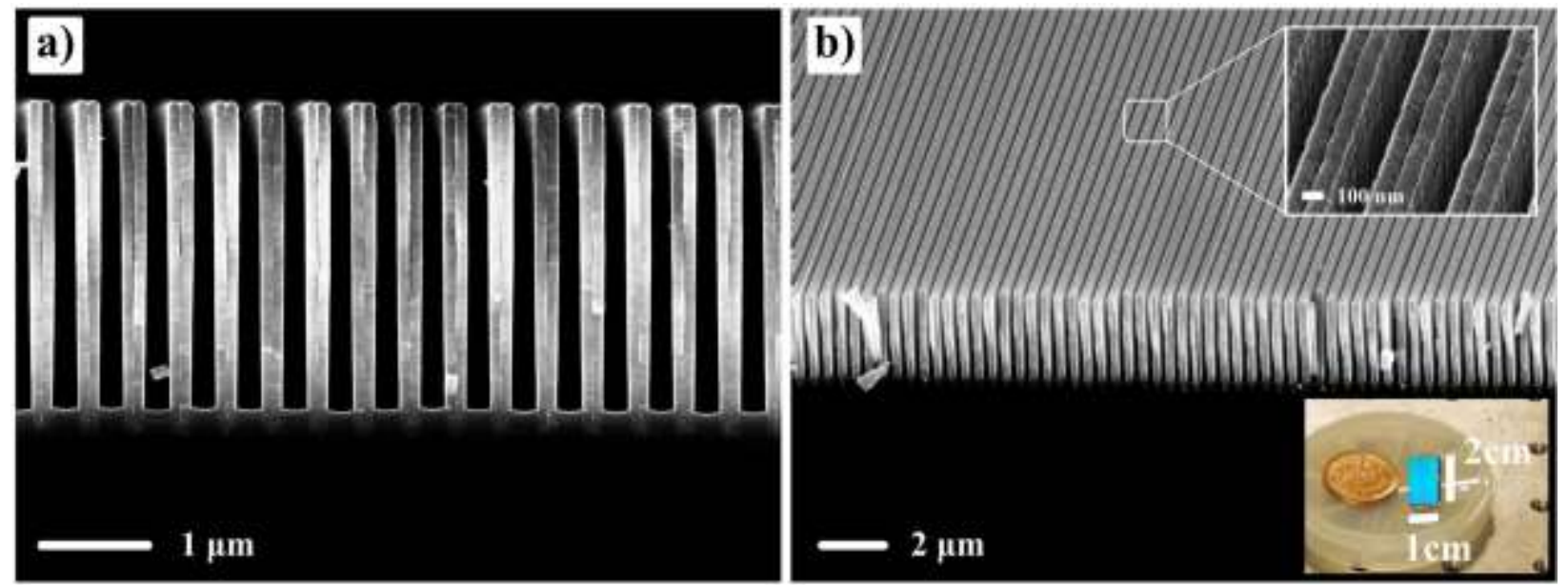

Fig. 1. Scanning electron microscopy images of the fabricated TiN trench structures. (a) cross section and (b) bird-eye-view (insets above and below show zoomed image of the top part and the photo image of the actual sample, respectively).

Here, we characterize the sensitivity of titanium nitride (TiN) high aspect ratio grating structures towards the refractive indices of different ambient liquids aiming for potential biosensing applications. TiN is a highly-refractory material that exhibits a plasmonic response in the visible and near-infrared (IR) wavelengths [4]. TiN is more abundant and cheaper than noble metals such $\mathrm{Au}$, and offer the possibility of tuning its permittivity by varying deposition conditions and post-treatment. Moreover, TiN films can be deposited by the atomic layer deposition (ALD) technique, enabling conformal deposition of plasmonic and dielectric layers with nanometer precision and as a consequence realization of large-scale metamaterial structures with exceptional uniformity in large areas [5].

Our TiN-based trench structures were realized by the combination of ALD with advanced deep reactive ion etching. The fabrication procedure is based on ALD deposition of TiN films on sacrificial Si templates with subsequential removal of $\mathrm{Si}$. TiN is deposited at $500^{\circ} \mathrm{C}$ on a silicon trench template with the pitch of $400 \mathrm{~nm}$ and height of around $2.7 \mu \mathrm{m}$. Silicon between vertical TiN layers is selectively etched to fabricate the high aspect ratio TiN trenches. Permittivity of TiN films with various thicknesses of $18-105 \mathrm{~nm}$ and post-annealing temperatures of 700 - 
$900^{\circ} \mathrm{C}$ is characterized by an ellipsometer. We found that the highest annealing temperature of $900^{\circ} \mathrm{C}$ gives the most pronounced plasmonic properties with the highest plasma frequency, $\omega_{\mathrm{p}}=2.53 \mathrm{eV}\left(\lambda_{\mathrm{p}}=490 \mathrm{~nm}\right)$ for the thickness of $105 \mathrm{~nm}$.

Grating structures can exhibit a sharp spectral increase in reflection, which is referred to as the Rayleigh-Woods anomaly (RWA) [6-8]. The spectral position of the reflection peaks associated with the RWA shifts depending on the changes in refractive indices of the surrounding media. We characterized the reflection peak associated with the RWA for different liquids, such as distilled water (DI), ethanol, and isopropanol (IPA). The bulk refractive index sensitivity of our sensing unit turns out to be $430 \mathrm{~nm} / \mathrm{RIU}$.

This work was supported by Villum Fonden "DarkSILD project" (11116) and Direktør Ib Henriksens Fond, Denmark. The authors would like to acknowledge the support from the Danish National Center for Micro- and Nanofabrication (DTU Danchip). O. T. sincerely acknowledges Dr. MD Stine Munkholm-Larsen, Resident Medical Officer, The Doctors in Gothersgade, Copenhagen K, Denmark for fruitful discussion and valuable comments on the possible detection of antibodies and proteins, and clinical diagnoses.
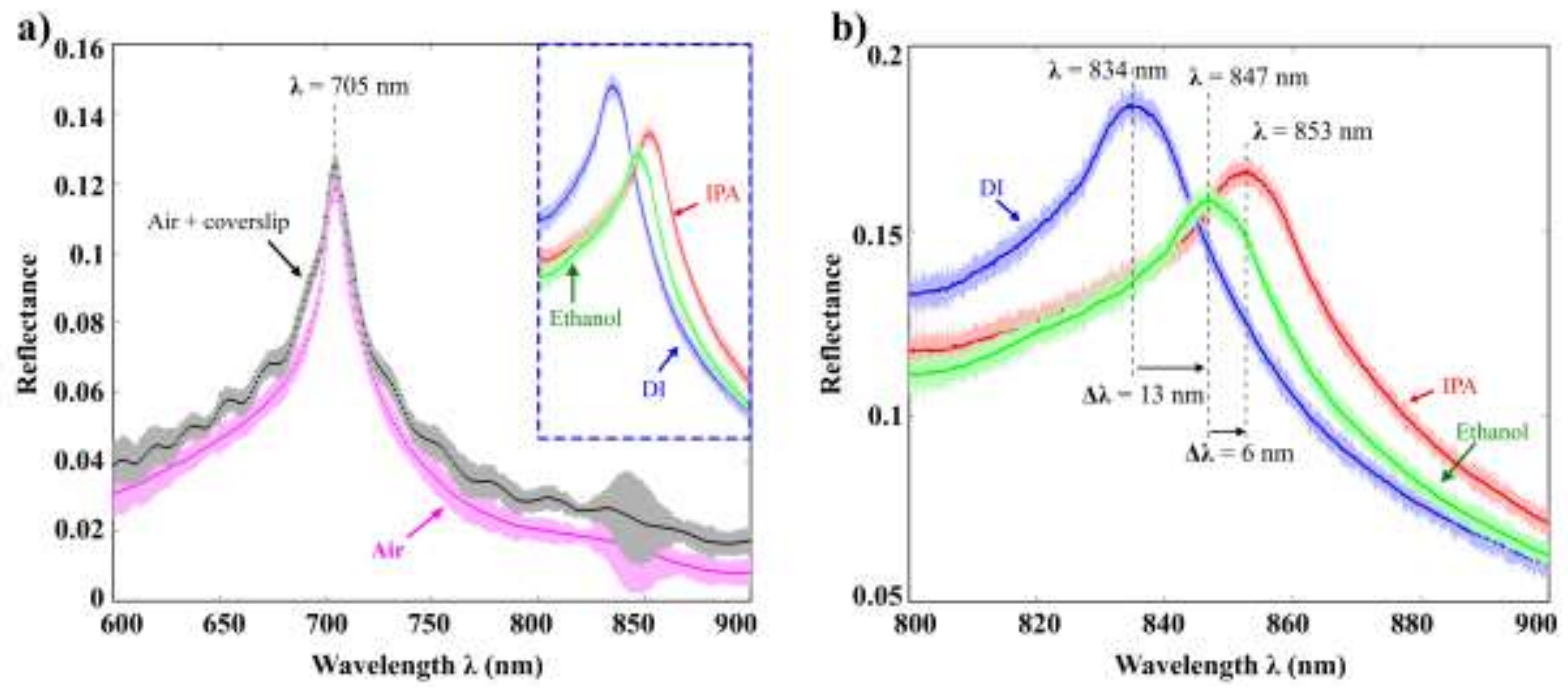

Fig. 2. Measured reflection from the TiN trench structures for different analytes such as air, distilled water (blue), ethanol (green), and isopropanol (red) in the wavelength range of (a) $600-900 \mathrm{~nm}$ and (b) $800-900 \mathrm{~nm}$. Note that the dashed square in (a) corresponds to (b). Refractive indices of distilled water (DI), ethanol, and isopropanol (IPA) are 1.327, 1.354, 1.371 in the wavelength region of interest, respectively.

\section{References}

[1] J. Homola, S. S. Yee, and G. Gauglitz, "Surface plasmon resonance sensors: review,” Sensors Actuators B Chem. 54, 3-15 (1999).

[2] C. Valsecchi and A. G. Brolo, "Periodic metallic nanostructures as plasmonic chemical sensors, Langmuir 29, 5638-5649 (2013).

[3] H. Inan, M. Poyraz, F. Inci, M. A. Lifson, M. Baday, B. T. Cunningham and U. Demirci, "Photonic crystals: emerging biosensors and their promise for point-of-care applications, Chem. Soc. Rev. 46, 366-388 (2017).

[4] P. R. West, S. Ishii, G. V. Naik, N. K. Emani, V. M. Shalaev, and A. Boltasseva, "Searching for better plasmonic materials," Laser Photonics Rev. 4, 795-808 (2010).

[5] E. Shkondin, T. Repän, T. Takayama and A. V. Lavrinenko, "High aspect ratio titanium nitride trench structures as plasmonic biosensor," Opt. Mater. Express 7, 4171- 4181 (2017).

[6] L. Rayleigh, “On the dynamic theory of gratings," Proc. R. Soc. Lond. 79, 399-416 (1907).

[7] S. Savoia, A. Ricciardi, A. Crescitelli, C. Granata, E. Esposito, V. Galdi, and A. Cusano, "Surface sensitivity of Rayleigh anomalies inmetallic nanogratings," Opt. Express 21, 23531-23542 (2013).

[8] M. Eitan, Z. Iluz, Y. Yifat, A. Boag, Y. Hanein, and J. Scheuer, "Degeneracy breaking of Wood's anomaly for enhanced refractive index sensing," ACS Photonics 2, 615-621 (2015). 